\title{
Aggregation Processes of a Weak Polyelectrolyte, Poly(allylamine) Hydrochloride
}

\author{
Jaejung Park, ${ }^{\dagger+}$ Young-Wook Choi, ${ }^{+}{ }^{\dagger}$ KyungBae Kim, ${ }^{\dagger}$ Hoeil Chung, ${ }^{\dagger}$ and Daewon Sohn ${ }^{\dagger *}$ \\ "Department of Chemistrv, Hanang Lniversit, Seoul 133-791, Korea. ${ }^{*}$ E-mail: dsohniahamang ac.hr \\ -Hair Care Research, Cosmetics \& Personal Care Research Center. AHORE-PACIFIC Corp., Yongin 4+6-729. Korea \\ $\$ R \& D$ Center, LG Micron. 1271, Ansan +26-791, Korea \\ Received August 1, 2007
}

\begin{abstract}
Poly(ally lamine) hydrochloride is a weak cationic polyelectrolyte that exhibits different aggregation properties at different solution $\mathrm{pH}$ values and aging times. Specifically. after several days aging in a $\mathrm{pH} 3$ buffer, less than $1 \mathrm{mg} / \mathrm{mL}$ poly(allylamine) hydrochloride became turbid, and the hydrodynamic radius increased with a single diffusion mode. However, the hydrodynamic radius did not change at ligh concentrations. The dynanuic processes of polymer aggregations at different $\mathrm{pH}$ values were verified by a light scattering and zeta-potential apparatus. The major interaction was caused by the capturing of counterions by the polyelectrolyte. which generates electrostatic, hydrophobic and cation- $\pi$ interactions
\end{abstract}

Key Words : Flocculation. Homogeneity parameter. Polyelectrolỵte. Probe charge effect. pH dependence

\section{Introduction}

The study of polymer aggregation dynamics is very important in the formation of the polyelectrolyte mutilayers through the layer by layer (LBL) and microcapsule templating method. The application of colloidal particles is often closely connected to the use of polyelectrolytes, which are widely used to stabilize or flocculate suspensions. ${ }^{3}$ For application in water purification, addition of small amounts of polymer results in attractive interactions, causing large flocculants to be formed by bridging interactions. ${ }^{2}$ In the food and cosmetics industries. a suspension or emulsion is generally the end product. A bio-mimicking polymer with an $\mathrm{NH}_{2}$ functional group. poly(allylamine) hydrochloride (PAH) has been vigorously studied for polystyrene sulfonate (PSS)/PAH multilayer formation due to the strong effect of salt concentration and $\mathrm{pH}$ on the conformational and mechanical properties. ${ }^{3-5}$ Composites consisting of a polystyrene (PS) core particle and PAH/PSS thin layer also showed potential as a drug delivery system. Although these composites have been widely used in several previous studies. little is known about the basic physical properties of weakly charged polyelectrolytes and hydrophobic anionic salts. ${ }^{6}$ The objective of this research was to reveal the intermolecular interaction and aggregation processes of a polyelectrolyte. $\mathrm{PAH}$. with various polymer concentrations and aging times by dynamic light scattering (DLS) and zeta-potential measurements.

\section{Experimental}

Materials. $\mathrm{PAH}(\mathrm{Mw}=70.000)$ and potassium hydrogen phthalate were obtained from Aldrich. A pH 3 buffer was prepared from $\mathrm{HCl}$ and $0.1-\mathrm{M}$ potassium hydrogen phthalate. $\mathrm{A} \mathrm{pH} 10$ buffer was prepared from $\mathrm{NaOH}$ and $0.025-\mathrm{M}$ borax. $\mathrm{NaCl}$ was added to each solution to maintain the same salt concentration as $100 \mathrm{mM}$ between $\mathrm{pH} 3$ and $\mathrm{pH} 10$ buffer solutions because ion, $\mathrm{Na}^{+}$. concentration is critical in the polyelectrolyte solutions.

Sample Preparation. Polyelectrolyte solutions were prepared by thoroughly mixing appropriate amounts $(0.05-10$ $\mathrm{mg} / \mathrm{mL}$ ) of PAH powder with $\mathrm{pH} 3 . \mathrm{pH} 10$ buffer or DIwater. $\mathrm{NaCl}$ was used to maintain salt concentration of each buffer solution. Double distilled, salt free water from a MilliQ system was used as a preparative solution. The dissolved solutions were stirred for several days. DLS was used to observe changes in the physical properties over the course of aging time. After PAH was dissolved in each buffer. the solution was filtered through a $0.8-\mu \mathrm{m}$ membrane directly into a pre-cleaned, light scattering cell $(13 \times 100$ num test tube). The measurements were performed daily for 30 days. For FT-IR analysis. the solution was dried in a vacuum and a dissolved solution was used for FT-Raman measurement.

Light Scattering Measurements. A Uniphase He-Ne laser with vertically polarized light of $\lambda_{1}=632 \mathrm{~nm}$ was used. The detector optics employed optical fibers coupled to an ALV/SO-SIPD/DUAL detection unit with an EMI PM-28B power supply and ALV/PM-PD preamplifier/discriminator. The correlator was an ALV-5000/E/WIN multiple tau correlator with 288 exponentially spaced channels. The sampling time of the correlator ranged from $10^{-6}$ to $100 \mathrm{sec}$. The cylindrical scattering cell was located in an index bath matching solvent (decaline) that was maintained at room temperature. The scattered light was passed through $400-\mu \mathrm{m}$ and $200-\mu \mathrm{m}$ pinholes. Two focal lenses and two GlanThomson polarizers were used. Each focal lens and polarizer pair were placed in front of the laser and pinhole. ${ }^{8}$ Each correlation function was gathered at six different angles from $\theta=30^{\circ}$ to $105^{\circ}$. For the static light scattering (SLS) experiments. intensities were measured from $\theta=30^{\circ}$ to $90^{\circ}$ in vertically polarized incident and scattered beam $\left(\mathrm{V}_{\mathrm{v}}\right)$ geometry.

Zeta Potential Measurements. The electrophoretic mo- 
bility of PAH represented by globular coll or aggregation was determined by photon correlation spectroscopy on a Zetasizer Nano ZS (Malvern Instruments. Malven, U.K.). Three rounds of assays were averaged. All measurements were performed at $25^{\circ} \mathrm{C}$. The mobility u was converted into $\zeta$-potential using the relation $\zeta=u l / e$, where $h$ is the viscosity of the solution and $\mathrm{e}$ is the pernittivity of the water solution

\section{Results and Discussion}

Dynamics of Aggregated PAH at Different pH Solutions. Figure $I$ shows the inages of PAH at different concentrations and age time. PAH and potassium hydrogen phthalate were chosen as the cationic polyelectrolyte and hydrophobic anionic salt, respectively. The aggregation behaviors depend on the nature of the lonic groups of the polyelectrolytes and salt. The salts in the $\mathrm{pH} 3$ and 10 buffers were potassium hydrogen phthalate and borax. respectively. ${ }^{\text {lo }}$ In this system the salt concentration was maintained and the only difference was the polymer concentration. achieved by adding PAH. The dynamic behavior of the polymer with different concentrations was studied by DLS and zeta-potentiometer.

In Figure 1. high degrees of aggregation (turbid state) were observed with long agung time at concentrations below $1 \mathrm{mg} / \mathrm{mL}$ PAH into $\mathrm{pH} 3$ buffer solution. The diffusion coefficients of turbid solution from DLS steeply decreased compared to initial transparent state, and the peak width of hydrodynamic radius $\left(\mathrm{R}_{\mathrm{H}}\right)$ distribution was narrow because uniform hydrophobic donains were fonned during the aggregation process.

Supplemental experuments were performed with $0.05,0.1$. $0.5 .10,2.0,4.0,5.0,10.0$ and $20 \mathrm{mig} / \mathrm{mL}$ PAH into $\mathrm{pH} 3$ and $\mathrm{pH} 10$ buffer solutions. But the aggregated PAH (turbid state) was only observed in $\mathrm{pH} 3$ solution. but not in $\mathrm{pH} 10$ solution

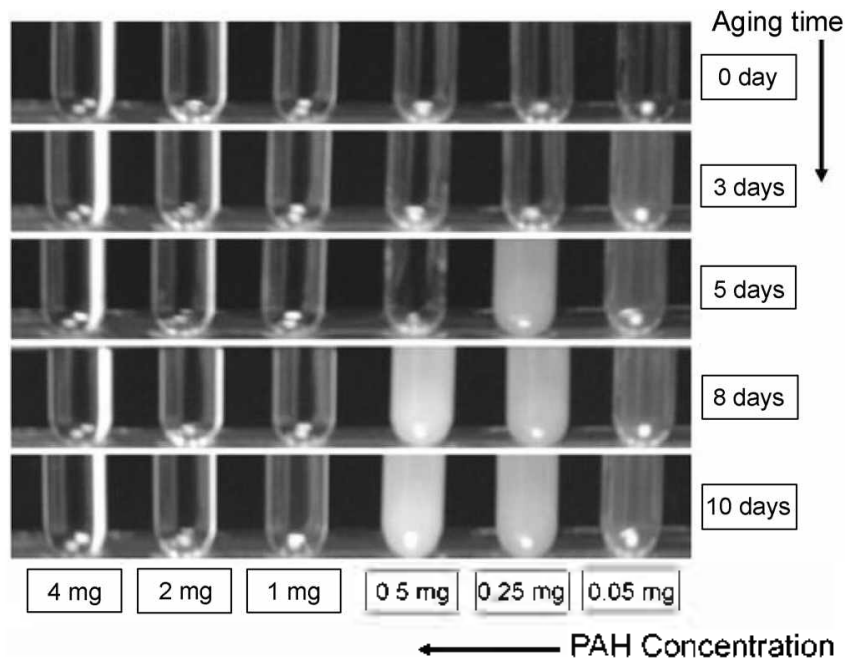

Figure 1. The turbidity change of $\mathrm{PAH}$ at various concentrations (bottom) and aging time (right) in $\mathrm{pH} 3$ buffer containing hydrophobic anionic salt.
The solution dynanucs of aggregated PAH (turbid state $\mathrm{m}$ $\mathrm{pH} 3$ solution) were investigated by light scattering and microelectrophoresis. PAH has different plysical property or structural conformation between the solutions of turbid and transparent state despite the PAH solutions at the same concentration. The diffusion coefficients and zeta-potential of aggregated PAH at the specific concentration which is transformed into turbid state with long aging time were measured at $\mathrm{pH} 3.5 .7$ and 10 by dilution of turbid solution with individual $\mathrm{pH}$ buffer solutions $(\mathrm{pH} 3,5.7$ and 10).

If $\mathrm{PAH}$ had an extended coil in the turbid solution, the diffusion coefficient of polymer into $\mathrm{pH} 5.7$ and 10 solutions would be mcreased due to charge screening. and it has similar tendency uto $\mathrm{pH} 7$ and 10 solutions due to neutral charge of functional group.

As seen in Figure 2, the diffusion coefficients with nonlinear single exponential fit were determined to be $1.86 \times$ $10^{-8}, 0.40 \times 10^{-8}, 0.163 \times 10^{-8}$ and $1.405 \times 10^{-8} \mathrm{~cm}^{7} / \mathrm{s}$ for $\mathrm{pH}$ 3. 5.7 and $\mathrm{pH} 10$, respectively. The $\mathrm{R}_{\mathrm{H}}$ of aggregated $\mathrm{PAH}$ deduced by the Stokes-Einstein (S-E) equation were 138. 621.1244 and $199 \mathrm{~mm}$ for $\mathrm{pH} 3,5.7$ and $\mathrm{pH} 10$. respectively. An $R_{H}$ of $138 \mathrm{~nm}$ corresponds to a primary aggregate. and 621 and $1244 \mathrm{~nm}$ correspond to secondary aggregates
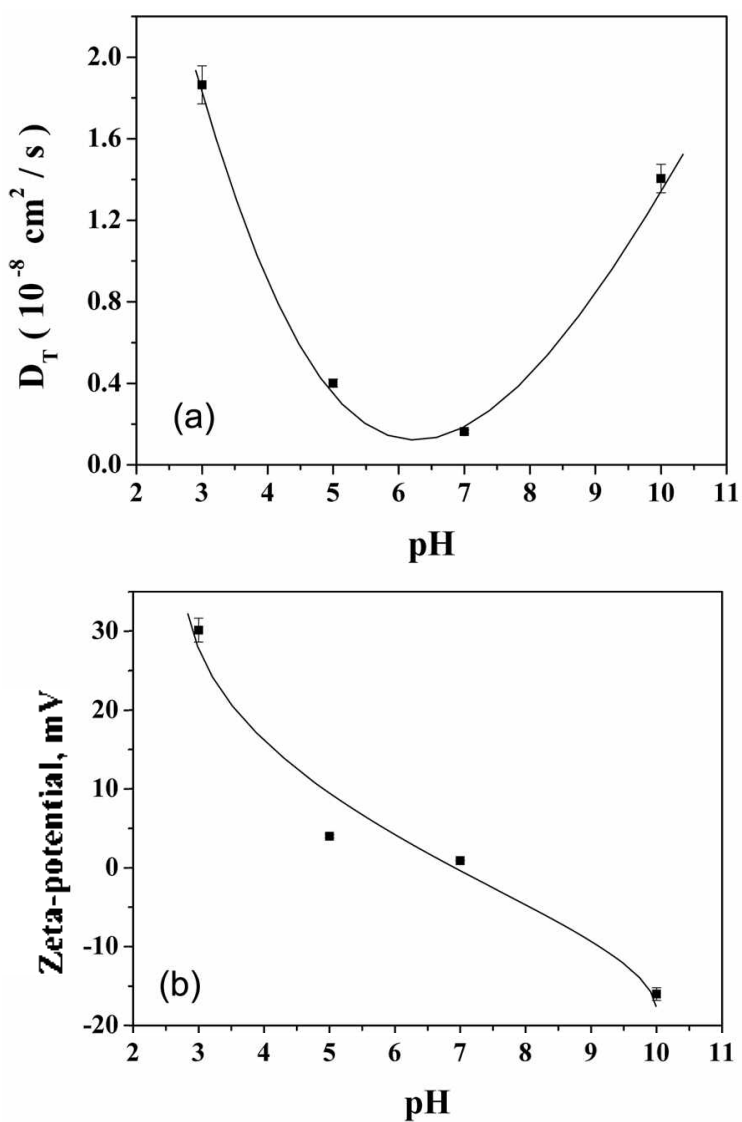

Figure 2. (a) Translational diffusion coefficients of aggregated $\mathrm{PAH}$ (turbid state, $1 \mathrm{mg} / \mathrm{mL}$ PAH into $\mathrm{pH} 3$ bufter after $\mathrm{l} 4$ days) with various $\mathrm{pH}$ solutions by DLS. An amount of $0.2 \mathrm{~mL}$ of aggregated $\mathrm{PAH}$ (turbid state) was mised with $2 \mathrm{~mL}$ of each $\mathrm{pH}$ buffer solution into pre-cleaned light scattering cell. (b) Zetá potential for each $\mathrm{pH}$ solution. (The line is just for guide.) 
formed by the small primary aggregates shown in Figure 2(a). This phenomenon was further elucidated by the microelectrophoresis experiment.

Figure 2(b) shows the magnitude of the zeta potential corresponding to the diffusion coefficient. which indicates the potential stability of the colloidal system. Although each turbid state had different $R_{H}$ and surface charge values. the aggregated PAH behaved as a particle with a specific domain. If all the particles in suspension have a large negative or positive zeta potential. the particles will tend to repel each other and flocculation does not occur. However, if the particles have low zeta potential values. there is no force to prevent the particles from coning together. resulting in flocculation. The most important factor that changes the zeta potential is $\mathrm{pH} .{ }^{11}$ The aggregated $\mathrm{PAH}$ in $\mathrm{pH} 3$ buffer has a highly positive zeta potential. suggesting primary aggregates were very stable due to repelling forces. If more alkali is added to the aggregated PAH. the positive charge neutralizes and the system becomes very unstable: the values of zetapotential are 4 and $0 \mathrm{mV}$ for $\mathrm{pH} 5$ and 7. respectively. When the conditions reached a higher $\mathrm{pH}$, the solution had a negative zeta potential, as low as $-14 \mathrm{mV}$. As a result, the aggregated $\mathrm{PAH}$ at $\mathrm{pH} 3$ and 10 had a stable colloidal system. The aggregated $\mathrm{PAH}$ at $\mathrm{pH} 5$ and $7 \mathrm{had}$ an unstable colloidal system with secondary aggregates, which were formed by bridging of the $\mathrm{pH}$ buffer. After a long aging time. the neutrally aggregated $\mathrm{PAH}$ precipitated and the stabilization was sustained at $\mathrm{pH} 3$ and 10 . The diffusion coefficient and zeta potential relationship proved that aggregated $\mathrm{PAH}$ (primary aggregate) has a specific domain and was affected by $\mathrm{pH}$ and ionic strength. Although PAH behaves like particles with aggregated domains. the aggregate maintains a high surface charge on the polyelectroly tes. ${ }^{12} \mathrm{~A}$ polyelectroly te conplex is primarily formed by the strong coulomb interaction between the oppositely charged polyelectrolyte and hydrophobic salt.

Time Dependent Behavior: Light Scattering Study. As observed with DLS measurement. the change of $R_{H}$ had not been observed into the PAH solution (every concentration which became turbid) without hydrophobic anionic salt. even over aging time of one month. In order to determine how the salt influences the equilibrium. the structural stability of $0.5 \mathrm{mg} / \mathrm{mL}$ PAH in $\mathrm{pH} 3$ buffer was studied over time. The sample was analyzed by DLS up to 30 days after the original sample preparation. Figure 3(a) shows the correlation functions of the PAH $0.5 \mathrm{mg} / \mathrm{mL} \mathrm{pH} 3$ buffer sy'stem with various aging times. The inset shows the relaxation time $(\tau)$ distributions of the PAH aqueous solutions at a scattering angle of $90^{\circ}$ using $\mathrm{V}_{\mathrm{v}}$ geometry. The $0.05 \mathrm{mg} / \mathrm{mL}$ $\mathrm{PAH}$ in $\mathrm{pH} 3$ buffer becane turbid after five days. At higher concentration than $0.05 \mathrm{mg} / \mathrm{mL}$. aging time longer than five days was required until being turbid. The $0.05 .0 .25,0.5 .1$ and $2 \mathrm{mg} / \mathrm{mL}$ PAH concentrations become turbid after 5.7 . 14. 18 and 30 day's. respectively. But the aging time to make turbid state is not exact time because the time period is so long. There are \pm 2 day deviations in the aging time. The $R_{H}$ distribution from the CONTIN-plot was monodispersed in a
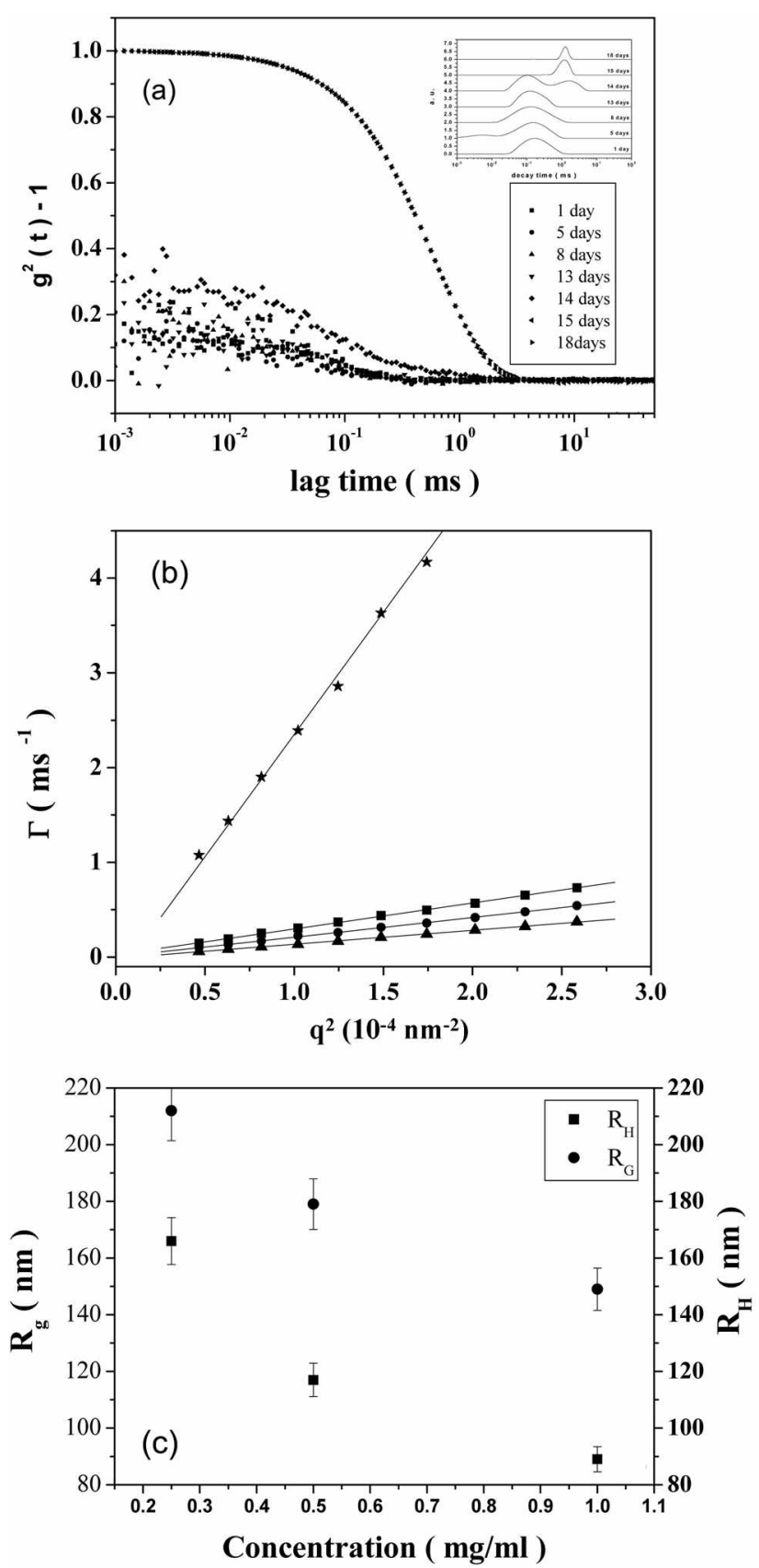

Figure 3. (a) Conelation functions of $\mathrm{PAH} 0.5 \mathrm{mg} / \mathrm{mL}$ of $\mathrm{pH} 3$ buffer in length of time until being turbid. The inset shows the relaxation time $(\tau)$ distributions of $\mathrm{PAH}$ solutions at a scattering angle of $y 0^{\prime \prime} 11 \mathrm{Vv}$ geometry. (b) Hydrod namic radius with various $\mathrm{PAH}$ concentrations. From top to bottom, $2 \mathrm{mg} / \mathrm{mL}, 1 \mathrm{mg} / \mathrm{mL}, 0.5$ $\mathrm{mg} / \mathrm{mL}$ and $0.25 \mathrm{mg} / \mathrm{mL}$. (c) Gyration radii and hydrodynamic radil into aggregated PAH solutions. $(0.25 \mathrm{mg} / \mathrm{mL}, 0.5 \mathrm{mg} / \mathrm{mL}, \mathrm{I}$ $\mathrm{mg} / \mathrm{mL}$ ).

concentrated state compared to the transparent state before aggregation. The polyelectrolyte and globular coils below 1 $\mathrm{m} g / \mathrm{mL}$ have a broad $\mathrm{R}_{\mathrm{H}}$ distribution. ${ }^{13.14}$ In the transparent state, a single diffusion mode was observed: however. the distribution of decay times was very broad with broad $R_{H}$ distribution. The increasing $R_{H}$ was caused by aggregation of the smaller molecular mass salt. The salt influence also depends on the molecule type and mixing ratios. The degree 
of aggregation was controlled by the addition of polymer during complex formation. The response time of the polyelectroly te complexes to a salt is very different, and strongly dependent on the polyelectrolyte components used..$^{15}$ It can not be fully explained why the aggregation time was long and turbid with respect to the multiplicity of this system. such as buffer ions. $\mathrm{pH}$ condition and $\mathrm{NaCl}$ salts. The change of conformation and interaction between potassium hydrogen phthalate and PAH will be discussed in terms of spectroscopic observations. In Figure 3(a), the single diffusion mode was corroborated by the sample turbidity as observed by DLS analysis.

The turbidity was not observed for concentrations greater than $2 \mathrm{mg} / \mathrm{mL}$. The PAH $2 \mathrm{mg} / \mathrm{mL}$ solution became turbid after one month of aging. The same system was observed for three months and a turbid state was not observed in the 2 $\mathrm{mg} / \mathrm{mL}$ solution. In Figure 3(b). the translational diffision coefficient changed regularly with concentrations. The diffusion coefficients were $2.6 \times 10^{-7} .2 .7 \times 10^{-8} .2 .1 \times 10^{-8}$ and $1.5 \times 10^{-8} \mathrm{~cm}^{2} / \mathrm{s}$ for $2.1,0.5$ and $0.25 \mathrm{mg} / \mathrm{mL} \mathrm{PAH} \mathrm{soll-}$ tions, respectively. The $\mathrm{R}_{\mathrm{H}}$ were $9.5,89,117$ and $166 \mathrm{~nm}$ for 2. 1.0 .5 and $0.25 \mathrm{mg} / \mathrm{mL} \mathrm{PAH}$ solutions, respectively. Generally, in polyelectrolyte solutions, two modes (fast and slow) may be observed. The physical origin of the slow diffusive process is not yet understood; however, it may be a result of the diffusion of large domains in the solution. The large domains can be formed by a number of molecules "incompactly connected" by electrostatic interactions. The PAH system was a transparent state. As mentioned above. the transparent state has a very broad $\mathrm{R}_{\mathrm{H}}$ distribution that contains fast (coil) and slow modes (connected molecule). SLS and DLS experiments can elucidate the $\mathrm{R}_{\mathrm{g}} / \mathrm{R}_{\mathrm{H}}(\rho$ parameter) ratio which indicates whether the polyelectrolyte presents as a randon coil (linear, polydispersed chain) or a domain. The literature value of $\rho$ calculated for an ideal random coil sy stem (lunear, poly dispersed chain) is 2.05 . For systems with gyration radii of 149.179 and $212 \mathrm{~nm}$. and the $\mathrm{R}_{\mathrm{H}}$ values of 89.117 and $166 \mathrm{~nm}$ for $1,0.5$ and $0.25 \mathrm{mg} / \mathrm{mL}$ aggregated PAH. $\rho$ was 1.67 .1 .53 and 1.3 , respectively. The experimental values were smaller than the theoretical. indicating the aggregated PAH (turbid state) exists as a structure with a well-defined domain rather than a random coil. ${ }^{16.18}$

The Interaction between PAH and Hydrophobic Salt. As the aging time increased. PAH formed self assemblies with potassium hydrogen phthalate. FT-IR and Raman spectra of the transparent and turbid state show some clues to solve this problem. The change from the transparent to turbid state was due to the potassium hydrogen phthalate. not $\mathrm{NaCl}$. The dynamic behavior of polyelectrolytes is much more complicated than that of the uncharged polymers due to the multiplicity of interactions present in the polyelectrolyte solution, the nature of which is not fully understood. However the polyelectrolyte effect was supposed to appear due to confomational changes of the molecules in the system. The turbid state only occurred at low concentrations (below $1 \mathrm{mg} / \mathrm{mL}$ ). Although potassium hydrogen phthalate is a small ionic molecule. the concentration was greater than that of PAH. The objectives of these experiments were to obtain information about the interactions between $\mathrm{PAH}$ and potassium hydrogen phthalate. The PAH solutions with various concentrations were prepared and incubated at room temperature until they became turbid. The objective was to observe the difference between a transparent and turbid solution with $0.5 \mathrm{mg} / \mathrm{mL}$ PAH. Figure 4 shows the $\mathrm{pH} 3$ buffer. (a), and aggregated PAH solution, (b, c). spectra compared to that of the standard potassium hydrogen phthalate.

The important PAH absorption bands indicating degree of ionization were found in the strong broad absorption band range of $2800-3250 \mathrm{~cm}^{-1}$ associated with the stretching mode of the $\mathrm{NH}_{3}{ }^{+}$group. The $\mathrm{PAH}$ bands indiscernibly overlap with bands associated with the $\mathrm{CH}_{2}$ asymmetric and symmetric stretcling modes. ${ }^{19}$ Changes in $-\mathrm{C}=\mathrm{O}$ carboxylate ion symmetric stretching were observed in the range of $1300-1450 \mathrm{~cm}^{-1}$, specifically near $1385 \mathrm{~cm}^{-1}$. In Figures 4(b) and (c). the $1385 \mathrm{~cm}^{-1}$ peak disappeared. due to ionic interaction of the carboxylate ion of the potassium hydrogen phthalate and amine group of PAH. The ratio of two peaks near $1700 \mathrm{~cm}^{-1}$ was different in Figures (b) and (c) due to a red shift ${ }^{20 \leqslant 2}$ For the turbid sample. the intensity of the right peak increased with respect to the left one. A peak shift was observed near $1600 \mathrm{~cm}^{-1}$ in ATR (transparent solution - $1687 \mathrm{~cm}^{-1}$; turbid solution - $\left.1665 \mathrm{~cm}^{-1}\right)$. The Raman spectrum of the solution was measured to obtain reliable data. For the transparent solution. specific interaction between PAH and potassium hydrogen phthalate was not expected. resulting in only a potassium hydrogen peak similar to FT-IR. It was difficult to measure the FT-Raman due to low intensity of the strongly turbid sample. such that when a small amount of PAH was added. the color changed from turbid to slightly transparent. Figure 5 shows the FTRaman spectra of PAH with step-wise addition of solution. The most important peak was near $1767 \mathrm{~cm}^{-1}$ which appeared only in the turbid state that was unrelated to PAH. A buried peak was expected to appear through peak shifting by interaction of the carboxylate group of the potassium hydro-

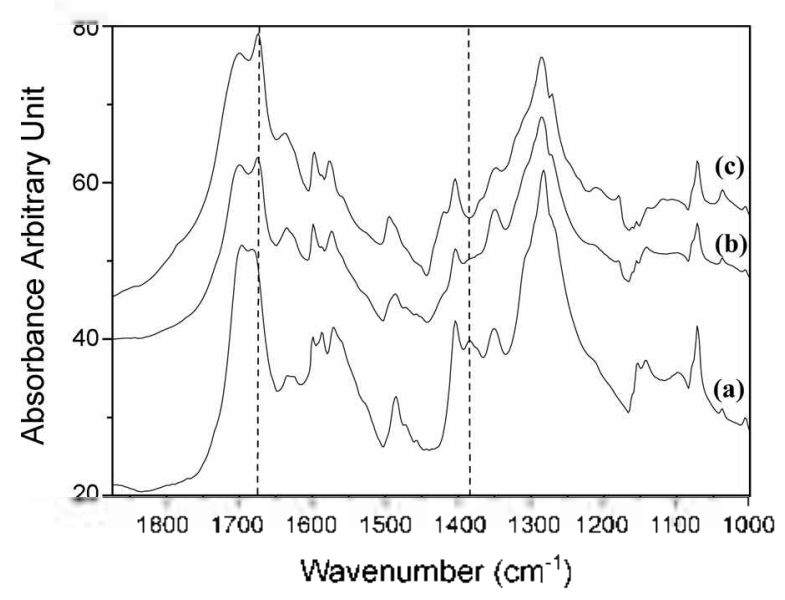

Figure 4. FT-IR spectrum of (a) $\mathrm{pH} 3$ butter solvent, (b) $0.25 \mathrm{mg} /$ $\mathrm{mL}$ and (c) $1 \mathrm{mg} / \mathrm{mL}$ aggregated PAH solution, (turbid state). 


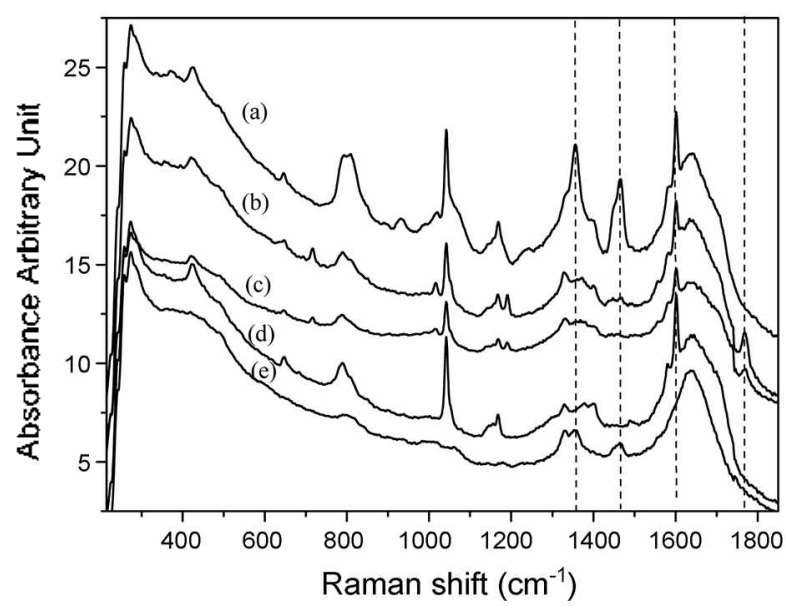

Figure 5. FT-Raman spectra of (a) PAH $50 \mathrm{mg} / \mathrm{mL}$ (transparent state), with (b) $5 \mathrm{mg} / \mathrm{mL}$ and (c) $9 \mathrm{mg} / \mathrm{mL}$ in $1 \mathrm{mg} / \mathrm{mL}$ turbid $\mathrm{PAH}$, (d) PAH $1 \mathrm{mg} / \mathrm{mL}$ (transparent state) in $\mathrm{pH} 3$ buffer, and (e) $10 \mathrm{mg} /$ mL PAH in DI-water (from top to bottom).

gen phthalate and amine group of PAH. The appearance of a new Raman peak at $1767 \mathrm{~cm}^{-1}$ indicated the PAH solution could be chemically changed by potassium hydrogen phthalate. due to the hydrogen bonding with the amine group of PAH.

Segregation of Aggregated PAH. As previously mentioned, the aggregated PAH acted as a charged particle with a specific domain due to a high concentration of the hydrophobic potassium hydrogen phthalate. The primary aggregate from the $\mathrm{pH} 3$ buffer altered with time and concentration. The change of solution dynamics was elucidated by addition of PAH powder to the aggregated PAH solution. ${ }^{23}$.

Figure 6 shows the correlation function of aggregated PAH $(1 \mathrm{mg} / \mathrm{mL}, \mathrm{pH} 3)$ in 6,12 , and 48 hours after adding PAH powder (extended coil state) of various concentrations in which the $R_{H}$ value decreased by electrostatic repulsion between the aggregated $\mathrm{PAH}$ and individual $\mathrm{PAH}$ chains.

Upon adding $\mathrm{PAH}$, the $\mathrm{R}_{\mathrm{H}}$ was unchanged until $12 \mathrm{mmg}$ $\mathrm{PAH}$, at which concentration the diffusion coefficient steeply decreased and the solution became transparent. At other concentrations. the decrease of diffusion coefficient depended on aging time. The forming rate of aggregated $\mathrm{PAH}$ was very slow, elucidating the self-assembly of the hydrophobic salt. potassium hydrogen phthalate. and electrostatic repulsion was a very slow process. With 4 and $5 \mathrm{mg} / \mathrm{mL}$, the $\mathrm{R}_{\mathrm{H}}$ was unchanged and the zeta potential was as high as $30 \mathrm{mV}$. The zeta potential value was unchanged over long aging times: however. above $8 \mathrm{mg} / \mathrm{mL}$. the diffusion coefficient increased and divided to a fast and slow mode upon addition of PAH. The zeta potentials of the samples with 4 and $5 \mathrm{mg} /$ $\mathrm{mL}$ were 36.1 and $34.85 \mathrm{mV}$. respectively. These values were similar to initial aggregated PAH solution. Upon increasing the amount of PAH the zeta potential decreased to $23.6 \mathrm{mV}(8 \mathrm{mg} / \mathrm{mL})$ and $23.72 \mathrm{mV}(12 \mathrm{mg} / \mathrm{mL})$, which were similar to the transparent state. Therefore adding PAH to the aggregated $\mathrm{PAH}$ solution caused a change from the turbid to transparent state. In the transparent sate the zeta
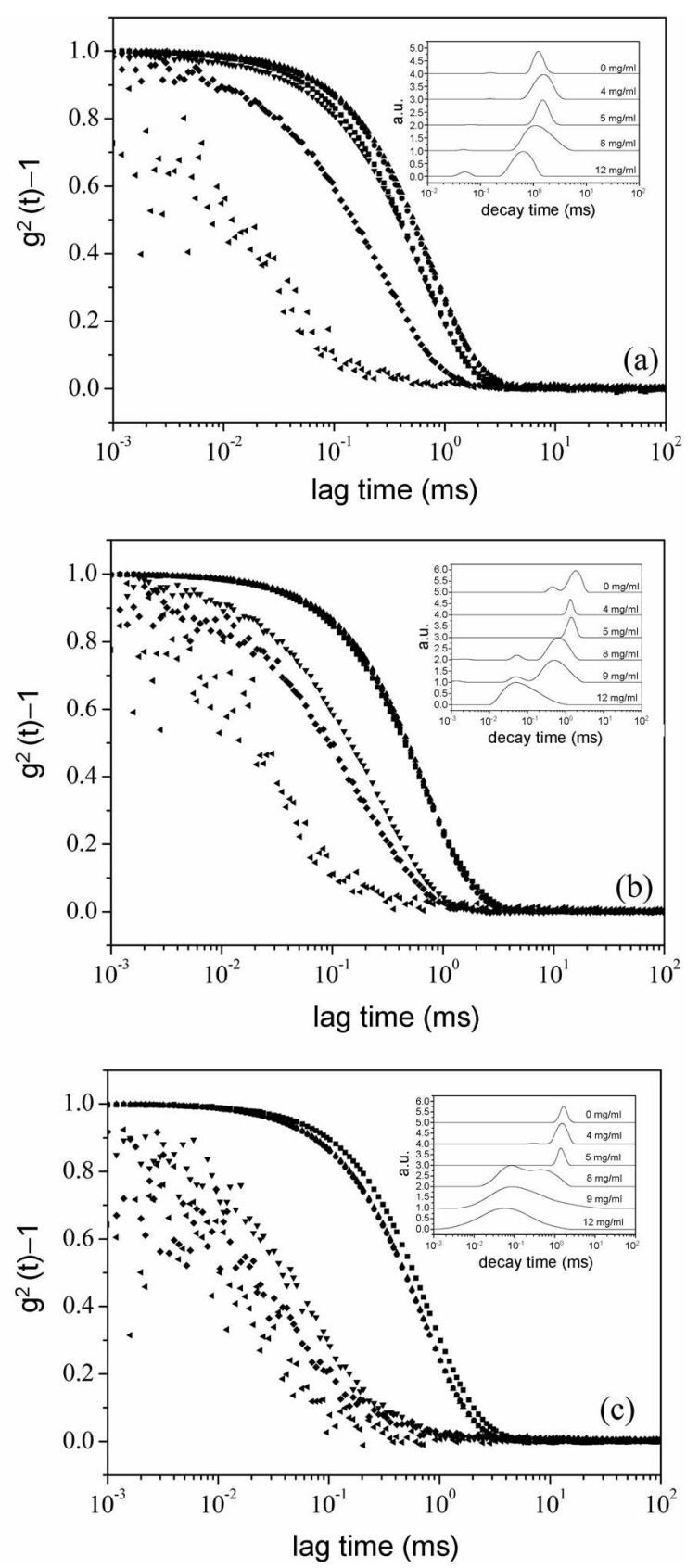

Figure 6. (a) Correlation function of aggregated PAH (turbid state, $1 \mathrm{mg} / \mathrm{mL}$ PAH into $\mathrm{pH} 3$ buffer after $\mathrm{l} 4$ days) in six hours after adding $\mathrm{PAH}$ powder with various concentrations. The inset shows the relaxation time $(\tau)$ distributions of aggregated $\mathrm{PAH}$ at a scattering angle of $90^{\circ}$ in Vv geometry ( no adding. $4 \mathrm{mg} / \mathrm{mL}$, - $5 \mathrm{mg} / \mathrm{mL}$, $8 \mathrm{mg} / \mathrm{mL}$, $9 \mathrm{mg} / \mathrm{mL}$, and $12 \mathrm{mg} / \mathrm{mL}$ ). (b) Correlation function of aggregated $\mathrm{PAH} 24$ hours atter adding $\mathrm{PAH}$ polyelectrolyte of various concentrations. The inset shows the relaxation time ( $\tau$ ) distributions of aggregated PAH at a scattering angle of $90^{\circ}$ in Vv geometry. (c) Conelation function of aggregated $\mathrm{PAH} 48$ hours after adding $\mathrm{PAH}$ polyelectrolyte of various concentrations. The inset shows the relaxation time $(\tau)$ distributions of aggregated PAH at a scattering angle of $90^{\circ}$ in Vv geometry.

potential was approximately $20 \mathrm{mV}$ without dependence on concentration. After adding $8 \mathrm{mg} / \mathrm{mL}$ PAH, the diffusion coefficient was unchanged. After 24 hours. the $\mathrm{R}_{H}$ began to 

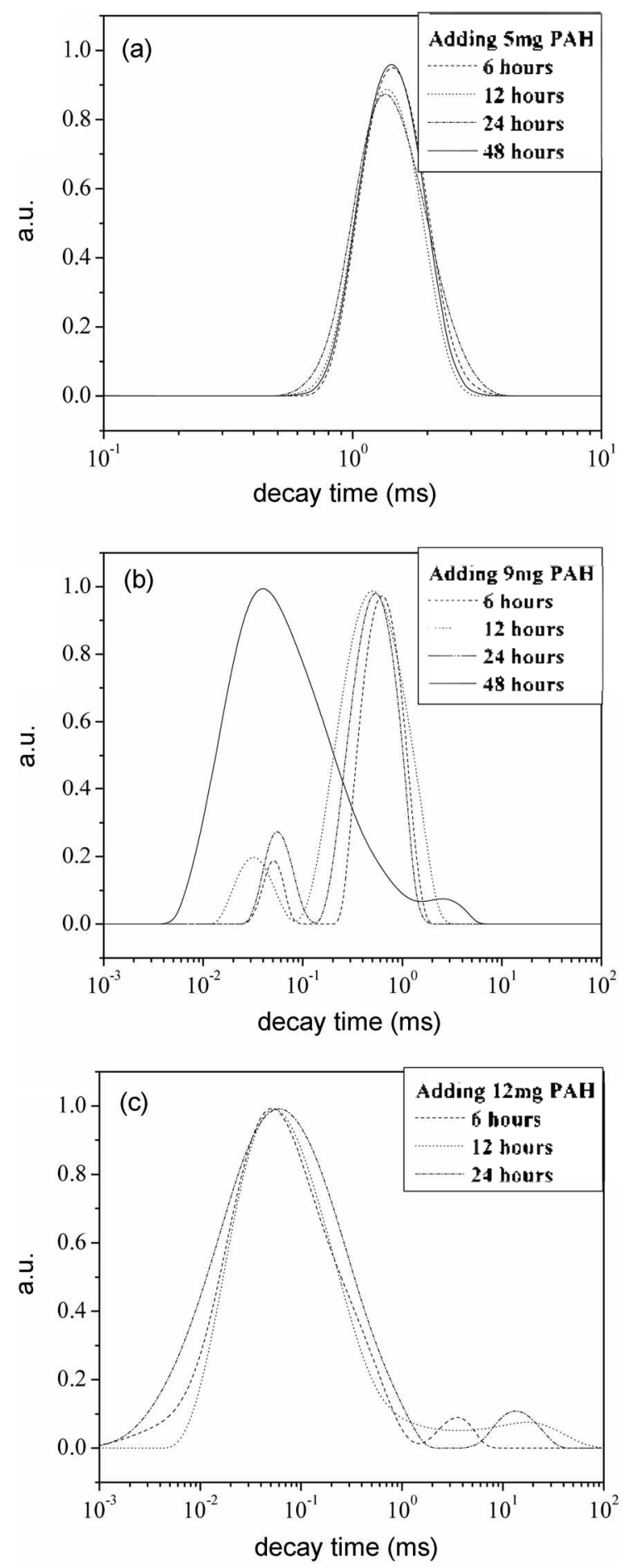

Figure 7 . The relaxation time ( $\tau$ ) distributions at a scattening angle of $90^{\circ}$ in $\mathrm{Vv}$ geometry. After adding (a) $5 \mathrm{mg} \mathrm{PAH}$, (b) $9 \mathrm{mg} \mathrm{PAH}$, and (c) $12 \mathrm{mg}$ PAH and the relation time was obtained every 6,12 , 24 , and 48 hours.

decrease, and after 48 hours. the aggregated PAH was segregated to individual and globular coils. The scattering intensity data in Figure 6 shows the supplemental expectation of the aggregated PAH. For the highly monodispersed or aggregated $\mathrm{PAH}$, the scattered intensity increased and the aggregated PAH had a very high light scattering intensity.
Table 1. Scattering intensity of aggregated PAH according to the amount of $\mathrm{PAH}$ powder and elapsed time. (same condition with Fig. 7)

\begin{tabular}{cccccc}
\hline & $4 \mathrm{mg} / \mathrm{mL}$ & $5 \mathrm{mg} / \mathrm{mL}$ & $8 \mathrm{mg} / \mathrm{mL}$ & $9 \mathrm{mg} / \mathrm{mL}$ & $12 \mathrm{mg} / \mathrm{mL}$ \\
\hline $30 \mathrm{~min}$ & 1833 & 1771 & 211 & 32 & 6 \\
12 hours & 1870 & 1800 & 65 & 22 & 5 \\
1 day & 1872 & 1767 & 33 & 19 & 5.5 \\
3 days & 1891 & 1777 & 9 & 10 & 6 \\
8 days & 1822 & 1778 & 7 & 6.5 & 5.6 \\
10 days & 1955 & 1713 & 5.6 & 5.6 & 5 \\
13 days & 1924 & 1733 & 5.6 & 5.9 & 5 \\
\hline
\end{tabular}

which steeply decreased at a specific concentration. To this end, the aggregated PAH was dispersed by the like charged polyelectrolyte. Figure 7 shows the corresponding relaxation time $(\tau)$ distributions at a scattering angle of $90^{\circ}$ in $\mathrm{V}_{\mathrm{V}}$ geometry after adding (a) $5 \mathrm{mg} \mathrm{PAH}$. (b) $9 \mathrm{mg} \mathrm{PAH}$, and (c) $12 \mathrm{mg}$ PAH. The relation time was obtained every $6,12.24$. and 48 hours. We could clearly observe the shift of the decay times by changing the concentration and aging time

Table 1 shows the radius distributions of Figure 7 corresponding to the scattering intensity data. Adding 5 and 12 $\mathrm{mg} / \mathrm{mL}$ PAH powder did not changed both radius distribution and scattering intensity. But the change by adding $9 \mathrm{mg} /$ mL PAH powder was proceeded slowly.

\section{Conclusion}

The dynamic behavior of polymer aggregation with potassium hydrogen phthalate and $\mathrm{NaCl}$ was investigated as a function of $\mathrm{pH}$ and aging time. $\mathrm{PAH}$ showed broad diffusion in dilute solutions. Upon increasing aging time, potassium hydrogen phthalate contributed to aggregation. and the diffusion coefficient steeply decreased with specific aging time. Although the system was complex, the alterable factors were limited to polymer concentration and aging time. The growth of aggregation under kinetic conditions over long aging times was difficult to understand and it was believed that the aggregated size initially formed by a shear field of stirring. When the shear field was removed by potassium hydrogen phthalate. the particles further aggregated. potentially due to hydrogen bonding or ionic interactions between the anionic hydrophobic salt and cationic polyelectrolyte. Evidence for the aggregation is due to the charge interactions. Although the flocculants were very strongly connected after long aging times. the rate of the formation was faster at low polymer concentrations. Notably, the $2 \mathrm{mg} / \mathrm{mL}$ PAH solution became turbid after one month. The conformation of aggregated PAH could be obtained from the $\mathrm{R}_{\mathrm{g}} / \mathrm{R}_{\mathrm{H}}$ ( $\rho$ parameter) ratio by static and dynamic light scattering. The ratio values were smaller than ideal random coils indicating the aggregated PAH (turbid state) existed as a well-defined domain rather than random coil.

Acknowledgement. This work was supported by the 
research fund from the National R \& D Project for Nano Science and Technology in Korea (KISTEP). DS thanks for the the ABRL program of KOSEF (grant \#: R-14-2002-00401002-0) and BK21 program.

\section{References}

1. Napper. D. H. Potwmeric Stabilization of Colloidal Dispersions: Academic Press: London. 1983.

2. Cohen-Stuart. M. A. Cosgrove. T.: Vincent. B. B. Adt: Colloid Interface Sci. 1986. 2f, 143.

3. Klitzin. R.: Mohwald. H. Langmuir 1995. H. 3554

4. Ibarz. G: Dahne. L: Donath. E.: Mohwald. H. Chem. Motter 2002. 14. 4059

5. Antipot: A. A. Sukhoruko: G. B. Adt: Colloid Interface Sci. 2004, 111, 49

6. Kesselnan. E: Raman, O.: Berkotici. R: Pax. Y. Polym Ads. Technol. 2002. 13. 1982

7. Boyko. V:: Richter. S.: Mende. M.: Schwarz. S.: Zschoche. S: Arndt. K.-F. Nacromolectat Chemisty and Phosics 2007. 208. 710.

8. Russo, P. S.: Saunders, M. I.: DeLong. M. L. Analutica Chimica Acta 1986. 189.69.

9. Loring. J. S.: Karlsson. M.: Fawcett. W. R.: Casey. W. H. Spectrochimica Acta Part t 2001. 57.1635.
10. Wu. H.: Kawaguchi. S.: Ito. K. Colloid Polyn Sici 2005. 283. 636.

11. Alami. E.: Almgren. M.: Brown. W.: François. I. J. Hacrontolecules 1996. 29. 2229 .

12. Healy, T. W. La Mer, V. K. J. Colloid Sci. 1964. 19, 323.

13. Wu, C: Zhou. S. Hacomolecules 1995, $28,5388$.

14. Siddiq. M.: Wu. C.: Liz. B. Joumal of Applied Pohner Science 1996. 60. 1995.

15. Hietala. S.: Parviainet1. H.: Anderssont. T: Tenhu. H. Proceeding of the 8th Polvmers for Aduanced Technologies Intemational Sumposium. 2005

16. Chelmecka, M. Complexes of Polvelectrolves with Defined Charge Distance and Different Dendimer Coumterions: Johannes Gutenberg Uniץ.: Mainz. 2004

17. Antonietti. M.: Heinz. S.: Schmidt. M.: Rosenauer. C. Machomolecules 1994. 27, 3276.

18. Krishnamoorthy: S.: Pugin. R.: Brugger. J.: Heinzelmann, H.; Hinderling, C. Ads: Fuct Mater 2006, 16, 1469.

19. York. S. S.: Buckner. M.: Frech. R. Hacronolecules 2004.37. 994.

20. Itano. K.: Choi. T.: Rubter. M. F. Machonolectles 2005. 38. 3450.

21. Mavrin, B. N.: Koldaeva. M. V.: Zakalyukin, R. M.: Turskaya. T. N. Optics and Spectroscopv 2006, 100.862.

22. Limberger, R. E.; Potemkin. I. I.; Khokhlov, A. R. Jounal of Chentical Phwsics 2003. 22. 119.

23. Joan11ya. T. F. Ent: Phus, J. B. 1999.9. 117 